\title{
FUTURE OF UTILIZATION OF WOOD FOR PULP AND PAPER IN CANADA
}

\author{
By M. WAYMAN ${ }^{1}$
}

I have decided to treat this subject quantitatively: How much wood are we required to get out of the woods?

I am going to speak only about pulp and paper, because that is the only part of the industry about which I feel competent to predict - that is, assuming that any human being has any competence to predict anything, which may be open to question. Pulp and paper, including newsprint, represents about 40 percent of all industrial wood harvested. My crystal ball speaks only about that 40 percent - I leave it to others to gaze into their own crystal balls. Let's toss this one up and see what happens.

Pulp wood, as you know, is used primarily in two ways: it is ground to make groundwood for newsprint and a few other uses, and it is chemically digested to make the chemical pulps - sulphite pulps or sulphate, that is, kraft pulps. To make a ton of groundwood requires about 1 cunit of wood; and to make a ton of chemical pulp requires about 1.8 cunits of wood. Recently chemical processes are making somewhat more pulp from less wood, and the 1.8 would be considered a high figure in some modern millsperhaps the average is 1.7 , and as time goes on, I expect that it will come down still further, perhaps to 1.6. But the main idea is that it takes quite a bit more wood to make a ton of chemical pulp than it does a ton of groundwood.

Pulp mills in Canada are expanding production rapidly - new mills are being built at a great rate. Canadian wood pulp production of the past few years is shown in Figure 1.

Some of the old standbys, sulphite pulp and the more glamorous dissolving pulp, appear to be at a standstill. But sulphate pulp, the new name for kraft pulp, is increasing rapidly, at the rate of 250,000 tons/A./A. in recent years, and groundwood, at about 70,000 tons/A./A. - or a total of 320,00 tons/A. each year. This represents an increase in wood utilization of 520,000 cunits per annum each year-a growth of about 3 percent per annum.

The sulphate pulp curve has some kinks in it. It turns ever more sharply upwards. I have listed the mills which are very likely to be built and the expansions which are very likely to take place in the next few years. You have heard a great deal about the new mills going up in Western Canada - the problem is to sort the wheat from the chaff. My crystall ball tells me that in 1969 Western Canada will be making 1,900,000 tons of pulp more than in 1964 and that this will require 3,250,000 more cunits of wood than are used today. Now Eastern Canada is not going to remain rooted to the ground during those years. I can see as highly probable 1,300,000 tons of pulp more in 1969 than today, requiring $2,100,000$ units more than in 1964.

\footnotetext{
${ }^{1}$ Professor of Chemical Engineering, University of Toronto, Toronto 5, Ont.
} 


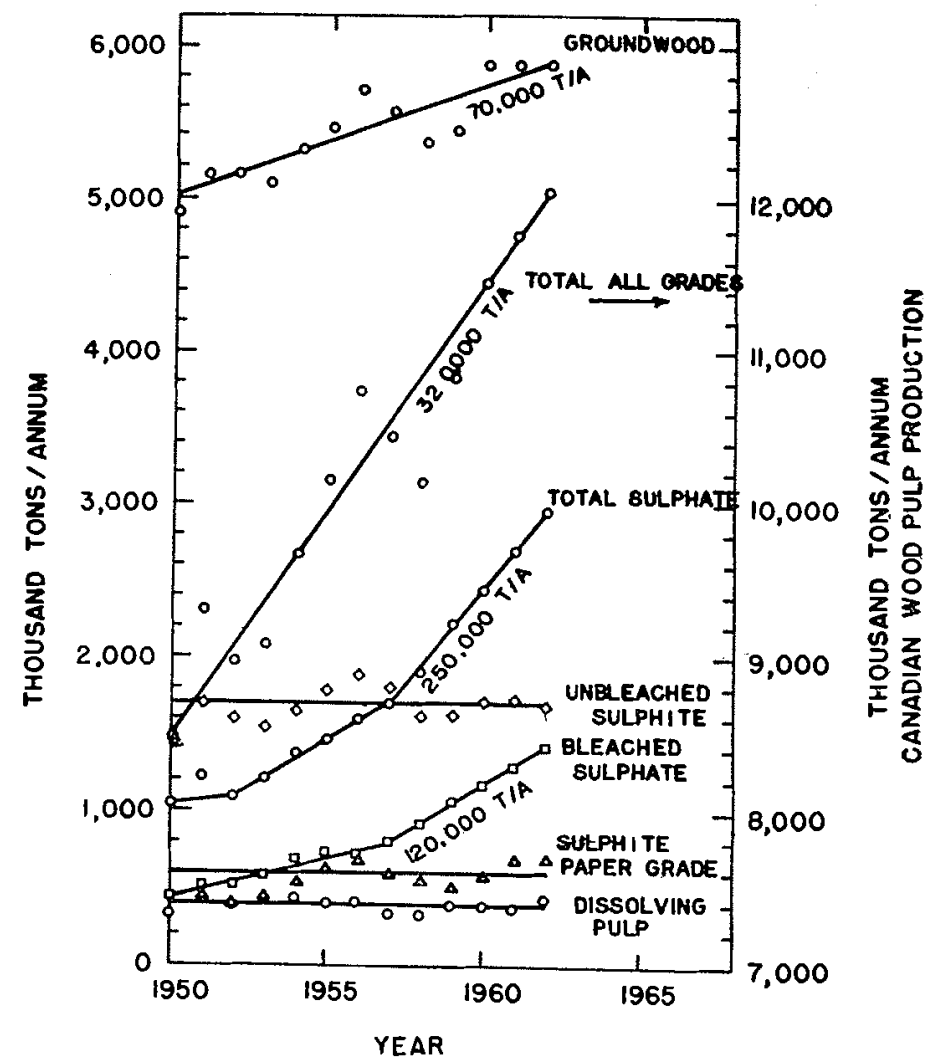

FIGURE 1. Canadian wood pulp production.

Altogether, by 1969 , Canadian foresters will be required to provide the pulp mills with about $5,000,000$ cunits of wood per annum more than they do today - a 30 percent increase in 5 years - or double the rate of increase in the last 5 years. This is my first point. It appears as though we have to prepare for a large haul — and it also means the industry is doing very well.

How do the demands made on Canadian foresters compare with the rest of the world? Figure 2 shows the rate of increase of pulp production in the principal producing countries of the world.

The Canadian rate has been 320,000 tons of pulp per annum per annum and for the next 5 years I am predicting 540,000 tons/A./A. The world total is rising at the rate of 3.0 million tons/A./A., of which the U.S.A. provides one-third. Finland has recently been increasing at the same rate as Canada, with Sweden at about two-thirds Canada's rate. Altogether Scandinavia, with roughly the same population as Canada, has been increasing pulp output at about twice Canada's rate, and this in spite of widespread gossip about these 


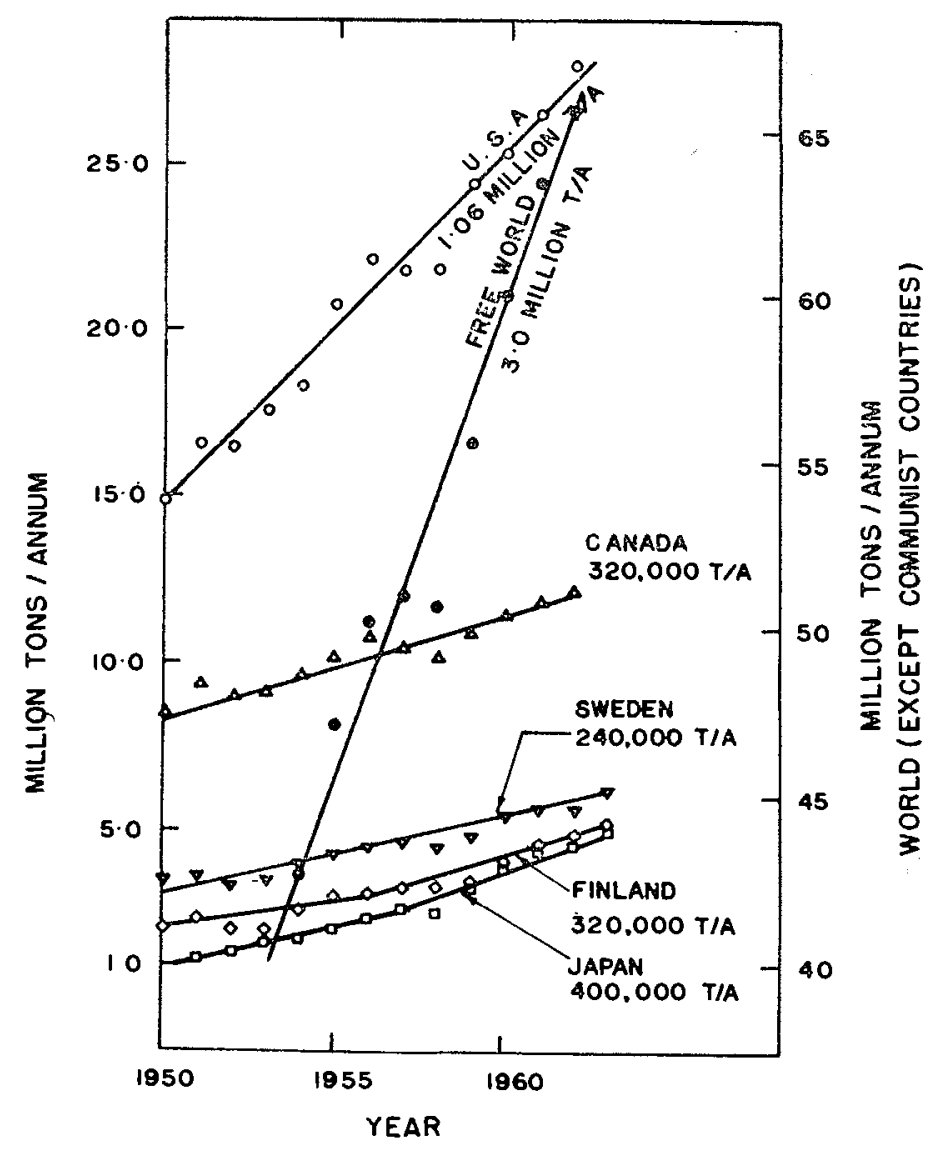

FIGURE 2. Rate of increase in wood pulp production in the principal producing countries of the world.

countries running out of wood. There is no evidence that the expansion of Scandinavian industry has stopped. Our wood resources are greater and we can surely sustain our rate of increase longer; but we have yet to demonstrate that we can build mills as fast as the Scandinavian countries.

The big surprise on this chart is Japan - 400,000/A./A. and increasing! This represents an annual increase of about 600,000 cunits of wood per annum: and this is on a small barren Pacific island. There are some ideas there which you can now discard - permanently and forcefully. In 1963 Japan made over 5,000,000 tons of pulp, of which 70 percent was chemical pulp and 30 percent groundwood, using about $8,000,000$ cunits of pulpwood, almost half of what Canada used in the same year! In addition 500,000 tons of pulp was imported, and total paper production was over 7,000,000 tons, the third largest producer next to Canada and the United States. In fact, Japanese paper production was about 80 percent of Canada's! 
Japan's consumption of pulp wood doubled in the last 5 years. How is this possible? The answer lies in their extensive plantation program. Anyone interested in forest plantations cannot afford to look lightly toward Japan their program is undoubtedly the most ambitious ever undertaken, and there is much that we and the foresters of the world have to learn from their experience.

My second point then is that while we have reason for pride in our rate of growth, and especially in the projected rate of growth -1 million cunits /A./A. - in fact, compared with Scandinavia and Japan our rates of growth have been considerably slower, and while our projected rate of growth will surpass that of Japan in the next few years, it will not attain the rate already achieved by Scandinavia. Let us not pause too long while congratulating ourselves.

My third point is in the form of a question - how long can these rates of increase be sustained? As far as raw material is concerned, Canada can go on as far as the eye can see. World use of paper outside of the U.S.A. averages 40 pounds per person per annum. Canada's consumption is 300 pounds per capita/A. If the rest of the world comes up to our level of paper consumption - and they would like to - 450,000,000 ton/A. of paper would be required - $7.5 \mathrm{x}$ present consumption (ex U.S.A.). Present and projected growth rates could be sustained at least 35 years and perhaps 100 years before the market becomes a limitation.

There is nothing in sight to slow up the Canadian industry barring the normal ups and downs in the short term.

The plantation program of Japan is being emulated on a smaller scale in South America, South Africa, Australia and New Zealand, and the Mediterranean basin. Is has a slight beginning in India and will eventually become important there. It is conceivable that in time these countries will have sufficient wood of their own to limit imports. This development will not affect our present markets - 85 percent of our pulp is now exported to the U.S.A. and the U.K. - but it could in the long run slow down our rate of increase of exports to other, new, markets.

The other factor which could, in the long run, slow down paper consumption is competition from other commodities. Nearly all pulp and paper is used for communications and for packaging, with lesser amounts used for textiles, construction and hygienic purposes. Competition for these end-uses is provided by electronics, such as radio and television, by plastics, synthetic fibers, metals and other packaging, structural and textile materials. This brings me to my fourth and final point: it is not at all clear that paper has maintained its position in our economy in relation to these other commodities, in terms of usefulness and in terms of relative cost or price. Combined engineering and economic research is required to establish the true reiative position of paper in our economy over the near past, to improve its relative cost and to enhance its usefulness in the future.

Some of the research and development has helped - new, faster paper machines, larger single line mills and more rational processing. One suspects, however, that all of this has served merely to keep us from falling too far back - we have been running hard to stay in the same place. Some of the 
new developments may however represent genuine advances - the new lightweight, opaque, white papers, the trend to higher pulp yields, the use of chips for groundwood and, one hopes, eventually single finish newsprint. These will improve the cost position of paper insofar as the paper makers bear this responsibility. From the point of view of the foresters, the cost of wood is a substantial portion of the cost of paper - about 35 to 40 percent of the mill cost of newsprint, about 45 to 50 percent of the mill cost of sulphate pulp. Improvements in wood costs would represent the greatest hope for cost improvement, increased utilization and long-term security.

To conclude - the future is bright - but the future belongs to those who work for it; and there is lots of work for us to do. 